\title{
The Role of Educator counsellor in Risk and Prevention Factors on Drug addiction among University Students (Analytical research)
}

Jaber M. Al-Hubaidah. Abdullah S. Alosaimi.

Prof. Assistant. Associate Prof.

General Authority for Applied Education and Training

Department of Psychology, Kuwait

Corresponding Author: Jaber M. Al-Hubaidah 


\begin{abstract}
Substance abuse is considered to be a phenomenon of drug abuse. Addiction describes the characteristic nature of this phenomenon as a devastating way in the concept of addressing the big problems or severe psychological anxiety of drug addicts. This phenomenon overlaps with every level or category of human society, but it is more prevalent among the general youth and university students; this phenomenon leads to many social crimes, where the phenomenon of drug addiction affects the rapid elimination of educational, cultural, moral and family importance. Moreover, an addict may become involved in large or even petty criminal acts aimed at collecting and using illicit drugs. As a result, young people, especially university students - the future of the country - are fast becoming the unknown. Regarding drug use as a personality disorder, it can be considered a disease related to hereditary development.

This research relates to the main objective of the main reasons for highlighting drug addiction among university students and determining the percentage of drug use among these students. The importance of these serious factors at the beginning of drug abuse is prominent, depending on the age of individuals, the level of the living environment, family relations, the way of raising children, the way they treat children and distinguish between them and other factors. Based on current research regarding the role of the educational counsellor on drug use of students, with the help of their families, use their experience, skills and services of time and energy directly or indirectly with these addicted students to maximize the effectiveness of the protection against risk factors that may prevent this phenomenon.
\end{abstract}

Key words: Drug addiction, anxiety, illegal drugs, educator counselor.

\title{
Introduction
}

Based on the form of an official document of the World Drug Report (2005) [1], the negative influences of the illegal drug abused trade affected every world society. The World Drug Report calculated that approximately 200 million users of age $15-64$, or $5 \%$ of world population consumed illegal drugs in the last 12 months at least once. The exploration of prohibitive drugs has increased all around the world nowadays. Furthermore, the statement concerned with that the world trend significantly is increasing the availability of many types of drugs to ever-expanding socio-economic sectors of consumers. The abuse drugs on a recognized social scale are alcohol, 
tobacco, Mira, and caffeine. Furthermore, illegal ones, such as heroin, cocaine and cannabis salivate, are considered.

The field of illicit substance markets has become larger, more extensive and verifying as never before. The World Drug Report (2018) [2] makes clear that international societies need to step forward to take part in the responsibility to overcome these challenges. With the production of opium and manufacture of cocaine, the world is facing potentially an expansion of drug market supply. As recorded at the highest levels, cocaine and methamphetamine markets are expanding to the far end of their usual regions. Although online using drug trafficking with the darknet proceeds and sustain to introduce only a small amount of drug trafficking and, instead of closing down the platforms of popular trading, it continues to grow quickly.

It was reported [3] that a drug use disorder is considered a medical illness depict by sufficiently clinically great disability in health, social duty, and noncompulsory control over drug abuse. Drug abuse disorders range in its seriousness with their period. Furthermore, its complexity is moderate to high intensity. However, 20.8 million people in 2015, aged 12 years and older, faced criteria for a drug abuse disorder. On the other hand, past history has indicated that a great number of treatment programs with little involvement have taken place in specially drug use disorder by general health care. However, for those with mild to average drug abuse disorders, a shift is in progress toward dispensing treatment at a general health care clinic. On the other hand, treatment with severe substance abuse disorders (addiction) might need a particular treatment.

\section{Problem Statement}

Aim of the study

The aim of this study is to describe the prevalence of illicit drug, to investigate and analyze factors affecting drug abuse and the role of educator counselor in risk and prevention factors among university students.

\section{The Study Objectives}

The research was conducted and guided by the following objectives:

- To survey the impact of peer continuous pressure exerted for drug abuse among students. 
- To locate the impact of possible availability of drugs on drug abuse through university students.

- To examine methodically and the constitution or structure of how mass media contributes to drug abuse through university students.

- To estimate nature and ability, how family discrepancy participates in drug abuse among university students.

- To counsel and inspect the role of advice by the educator with the aim of resolving the problem and difficulty in controlling drug abuse among university students.

\section{Research Questions}

The study seeks to reply to the following research questions:

- How do peers use persuasion and influence, or intimidation to make the person contribute to the drug abuse of among university students?

- How does the possible availability of drugs participate in drug abuse among students?

- How do families combat and discrepancy participate in drug abuse through university students?

- What part goes for resolving and guiding the problem with its difficulties and possible counselling actively engaged in controlling drug abuse through university students?

\section{Significance of the Study}

- The feedback obtained from the present research might assist the high level authorities, Ministry of Education and the civil society organizations to understand the present circumstances of drug abuse.

- The research might support policymakers, instructors, educators and executives becoming perceptible of factors that prevent current access to suppression of drug abuse.

- Family and protectors might utilize this study by acquiring conception on their student's use of drugs to be preferable position to guarantee good treatment and instruction of their teenagers.

- The current research might be of intensity considerably important to the curriculum entrepreneurs in the higher Education university.

- This research might, reveal new research that may work as a foundation for future investigation that might be willing to 
examine this field for furthermore and consolidate other particular parts not exposed in the investigation.

\section{Limitations of the study}

- Concerning drug abuse, some university executives may indicate or show that they aren't willing to give records that might be necessary by the researcher.

- Some of thus, the actual levels of perceived social support cannot be discriminated against by respondent categories that may not collaborate with the researchers.

- The respondents might give fake or incorrect information to the articles in the questionnaire.

However, the authorities from the Psychological counselling suppose to confirm that the data obtained should be considered as confidentiality and will be used for only the purpose of the involved research.

\section{The Study Assumption}

- Drug abuse influences student's to affect their academic performance in the University.

- The respondents supplied the correct and real data information about the case.

- The collected sample under investigation performs all the inhabitants.

- The abused Substance is willingly available and easy reach to the university students.

\section{Review of Literature}

EMCDDA (2010) [4]has been carried out an investigation showing that one in three of 12 year old had been approaching drugs in Scotland. The Scottish Parliament's Angus Mackay, the Deputy Justice Minister, reported that children in their first year of secondary schools were especially susceptible to harm from drug dealers as they left their known primary school friends and were obliged to make new friends. The United Kingdom, however, has not been far away from the drug threat. Jason Allardyce, a Scottish political reporter that in a Govan primary school, a case of heroin was found in an eleven year-old boy in his school bag.

Dawson (2019) [5] reported that twenty-three million young people over the age of 12 are suffering from the criteria for substance abuse. The overdose drug is currently the main cause of damage- 
related end to life in the USA. As a result of overdoses related to opium like compounds, almost 218,000 people died of 1999 to 2017. In 2017, overdose deaths related to opium were five times higher than what occurred in 1999. $\$ 700$ billion annually is the financial cost of substance improper use in the USA, as estimated. Graduate student level education has been shown to increase the substance abuse practice. However, most US states demand less than the average educational counsellor's necessities for substance abuse.

Zaman et al., (2015) [6] by his research for drug addiction purposes, they have chosen different educational institutions inclusive "the university of Lahore", (private sector) and Punjabi University (public sector) and carried out a survey among 500 students. High ratios of students were found abusing drugs. The study revealed that multiple circumstances where the substantial cause of drug abuse was in medical students comprehensive depression, anxiety, schizophrenia, in addition to personality disorder as if personality antisocial disorder. The survey has shown that a high rate of illegal and a medical practitioner that authorizes a patient to be provided a medical drugs treatment. For this entire drug misuse among college students, few have evaluated the negative outcomes, or eagerness to intervene for drug use.

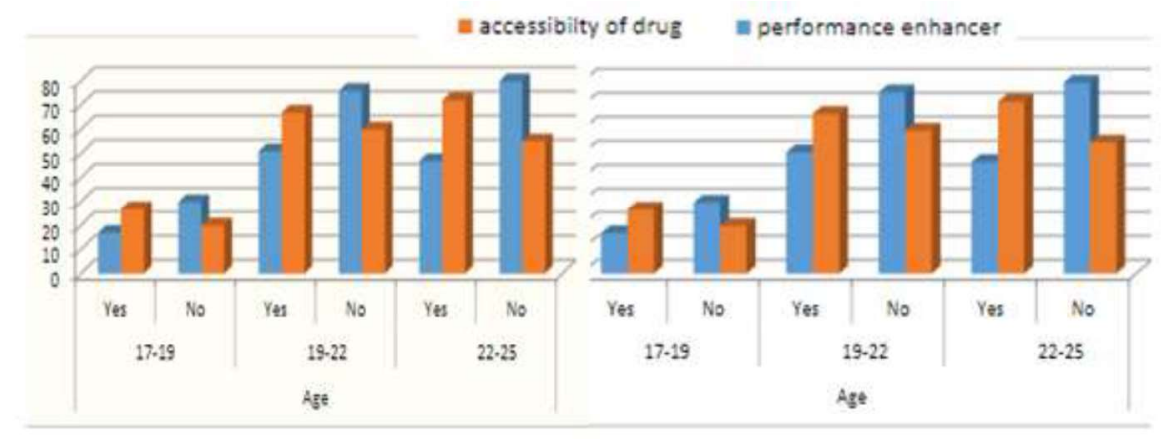

Fig (1)

Fig (2)

Comparison of different parameters as accessibility of drug and performance in-between students of educational institute of public and private sector as shown in fig (1) whilst a Comparison of different parameters between students of educational institute at different age group as shown in fig (2).The study showed the most drug abusers are males in comparison to females. On the other hand, 
the ratio of the private sector in students of the drug abuse presented higher than the public sector.

New York State carried out a multiple methods investigation to search for these types of barriers to higher education through substance addiction counselors. In a total of 124 volunteers, a considerable correlation was spotted between counselor's willingness to follow a graduate student level and their confidence in approaches results versus traditional 12-step ideology. Material and philosophical institutional support were significantly correlated with intentions to further one's education. Based on these findings, recommendations for treatment and policy are provided.

Maithya (2009) [7] has proposed that since drug use is many and various, there is no particular convention, about the reasons for drug abuse. Several factors include individual, family discriminatory, environmental and social factors. Many different models have been introduced but the most common one of the models that explains addiction reasons are mixed factors such as biological-psychical and social model. In this sort of model, addiction is proposed as disease, performed of various factors and arranged in advance as dangerous factors. By individuals, this factor introduced as influential factors at addiction beginning and performing drug abuse.

Botvin (2013) [8] assigns drug abuse between youth to the feelings formulated by drugs, leverage from friends and family kin, testing, pharmaceutical use and emotional stress.

Many studies have investigated the educational role in the employment of testimony-based on the actual application, but little is understood concerning the multiple obstacles' substance addiction counsellors practical contact. New York State carried out a multiple method investigation to search for these types of barriers to higher education through substance addiction counsellors. In a total of 124 volunteers, a considerable correlation was spotted between counsellor's willingness to follow a graduate student level and their confidence in approaches results versus traditional 12-step ideology. Material and philosophical institutional support were significantly correlated with intentions to further one's education. Based on these findings, recommendations for treatment and policy are provided.

An investigation has been done by the National Agency for the campaign Against Drug Abuse (NACADA) (2008) [9]reported that 
up to 92 percent of young people 16 and 26 years old are registered to have adapted to drugs, and more than 50 percent of those halted the drugs, but 25 percent continue abusing the drug substance. About 20 percent of these young people reported ending up getting addicted and unable to stop taking it without incurring adverse effects, and drug abuse has turned into an international problem that intimidates many lives on earth. Nations Secretary General, announced that; "Drug abuse has increased rapidly and dramatically in recent years. Most drugs are taken by young, poor or both. No Nation is invulnerable by the highly destructive consequences of drug abuse, an upward surge in crime, forbidden trade, violence and the devastation of the individual, corruption, families and entire societies and weakening of national economies. Substance or drug abuse is negatively influencing the quality of education in the nation's schools; from the primary level, to Universities.

Abul-Hasam and his colleagues (2017) [10] in experimental results conducted that the majority $(67.67 \%)$ of drug addicts consider that the addiction of drugs is high/very high, at the same time. $9.10 \%$ medium and at the same time.23.23\% low/very low due to the influence of the feeling of being upset or annoyed, especially because of inability to change or achieve self-consistency with his peer group in society.

Glynn (1989)[11], DHHS (2000)[12] \& Susan and her colleagues (2004) [13] conducted school-based drug use prevention programs that have been an integral part of the US anti-drug campaign for the past two decades. DARE uses specially trained law enforcement officers to teach drug use prevention Curriculum in elementary schools.

Steven (1988)[14] Project D.A.R. E curriculum's 17 lessons, usually offered once a week for 45 to 60 minutes, focus on teaching pupils the skills needed to recognize and resist social pressures to use drugs. In addition, lessons focus on providing information about drugs, teaching decision-making skills, building self-esteem, and choosing healthy alternatives to drug use.4 DARE officers use teaching strategies, such as lectures, group discussions, question-andMost of the drug use prevention programs evaluated by the university research-based evaluation studies, whereas DARE is a commercially available curriculum. Although the magnitude of the resources invested in DARE is considerable, the intensity of effort devoted to 
smaller-scale programs may be greater. Any diminished effectiveness is perhaps inevitable once programs are widely marketed.

Adroom (2016) [15] has shown that drug abuse is intimidation to the society as well as to the young students consequently, it is clear that drug abuse in between students and society, in general, should not be overlooked or missed and be taking part in a violent struggle to always involve to prevent substance abuse and connected problems at all standards, in the society. His research study was to collect qualitative and quantitative data information as a descriptive survey. The data information was using a set of printed and written questions with a choice of answers. The survey was completed with interviews. This survey originated as a statistical study. Both approaches, however, were used in data analysis. Eventually, those mixed paradigms research design process were to collect data analysis using the Statistical Program (SPSS).

Abul-Hasam and his colleague (2017)[16] aimed to investigate the relationship between frustration possibility and inclination toward drug abuse among students. The research study consisted of 170 random samplings from among students of Zahedari PNU. The questionnaire about frustration tolerance and addiction possibilities and the conducted data obtained were analyzed. In this investigation two models of collected data library and field investigation were designed for a statistical survey study. By using the Pearson coefficient of correlation and by SPSS regression software the results have been conducted. The results demonstrated that the lack of success allowance and the existence of the drug significantly positive. They concluded that the two factors - education, and tendency, to use drugs to show no relationship.

Yusuf (2011) [17] reported in her investigation the factors have an influence on substance abuse through university students using questionnaire for investigating the Factors Involving Substance Abuse (FISA) to collect the appropriate data. Eventually, the datacompiled and analyzed using a simple percentage, t-test and Analysis of Variance (ANOVA). Her research findings show that peer impact is a major factor that has an influence on substance abuse among university male and female students. The research exposed that there is a considerable divergence between either male or female influencing substance abuse factors. Yusuf proposed that counselors 
should arrange structured different programs to actively encourage healthy living of the university students.

Bechara (2005) [18] \& Wing et al.; (2019)[19] \&.reported that youths are liable to be influenced by the peer impact of drug abuse. On the level of interpersonal factors, however, might influence youths' sexual adultery. It was indicated by Western studies that substance abuse is connected with different factors, containing inappropriate decision-making, absence of self-confidence, and invalidation of society's negative judgment of sexual behaviour. The results of his research show that substance abuse is sufficiently great connected with sexual adultery. Furthermore, young students are liable to be influenced by peer impact and school engagement. Depending on this conclusion, the participation is that, if the event is to improve young student health and prevent sexual adultery, then it is relevant that substance abuse with precautionary interference as implemented programmes are to be carried out.

Mikhail et al.; (2001) [20] carried out an investigation to estimate the psychosocial scene behind the main object of contemplation of the drug addiction problem in

Assiut Governorate. The study contained 50 drug addicts from the Social Defense Club of Assiut psychiatric and addiction unit at Assiut University Hospital. Further, control groups of 50 of their families. For drug addicts, the collected data was about (1) family background history and socio-demographic; (2) the style of abused substance (3) mental features check list-90 (SCL-90); (4) the conditions Drug taking and sorts used. The study disclosed that drug addicts were distinguished by a relatively young age (average 25 years), minimum education and social level. Their family relationships were aggressive, overcritical as well as overprotection, social pressure, unpleasant emotional status and serious disagreement with others. At a young age they commenced drug abuse. The major factors for abuse were peer impact, testing, and anxiety and disquiet, strongly wishing for calmness and excellency. The study revealed that the existence of social health nurses is to support health education for protection, of addiction in social defence clubs and of their combination, into enhancing, health programs.

Abdel-Mageid (2017) [21] reported that an investigation of 427 transporter drivers; has revealed that $20.8 \%$ of them were positively addicted. During the same period of experimental work, the same 
population was adopted as a control group and was arbitrarily chosen from patients. It was found $22 \%$ has been positively forbidden drug abuse. Furthermore, it was found that there were no considerable differences in the commonness of substance abuse between the two groups. In addition to that, it was found that Cannabis was the most prevalent drug abuse among drivers almost (59.6\%). However, a sufficiently great increase among the control groups which is almost (40.4\%) consumption of tramadol. It was concluded that Cannabis was the most forbidden drug frequently consumed among drivers.

Chadda and his colleagues (2018) [22] \& Alvarez et al. [23] explained that Addictive disturbances generate a robust psychosocial component. Psychosocial approaches, however, form a considerable part of controlling or planning of prevented and retrogression treatment roles. Long term rehabilitation is, therefore, required. Normally, the patients often have strong resistance as well as the families against treatment. It is often a disorder to become aware or conscious of a bad habit [24]. Consequently, the treatment considered is not requested. It's substantial to violate this barrier to fetch back the family and the patient to be involved in treatment. The treatment was identified as three psychosocial interventions [25]:-

Assistance ' Identify ' Addiction Cases by:

- Reducing substance used by the rate of occurrence and quantity.

- Reducing the associated risk with an addictive attitude.

- identify the limited Time intervention for the risky of substance abuse users or addictive attitude.

\section{The Enhancement of Therapy Motivation}

- Increase motivation by resolving duplicity engagement.

- Handling, and, obligation to stop drug abuse by transfer from one stage to another.

\section{Assistance throughout Treatment}

- Prevention relapsing.

- The therapy of Cognitive attitude.

- Interventions dependent family.

- Assistance to Sustain and Keep Possession of Treatment

- Contingency management-

- Self-help group

Jonathan and his colleagues (2016) [26] and Fuligni (2001) [27] provided that a highly significant relationship between adolescent addictive inappropriate behaviour and parent drug abuse. 
Furthermore, a significant positive influences the relationship of the peer group on adolescents' addictive by inappropriate behaviour. It was proposed that parents should pay a significant part on the kind of adolescents' behaviour they display before their teen-ages should be guided by their nominee of friends.

Naz (2015) [28] reported in his thesis that drug abuse and reliance are both, therefore, called substance use disorders. Physical reflections like arrhythmia, nausea, paranoia, poor decision-making like risky sex, danger of injury or death and driving concerning accidents are the main cause of abusing substance. He exposed factors such as the biopsychosocial model of health affecting substance use disorder such like as shown in fig (3):

- Quality of Life (QOL),

- Biological Health,

- Psychological health,

- Environmental health,

- Social relationship and

- Causes for abusing substance

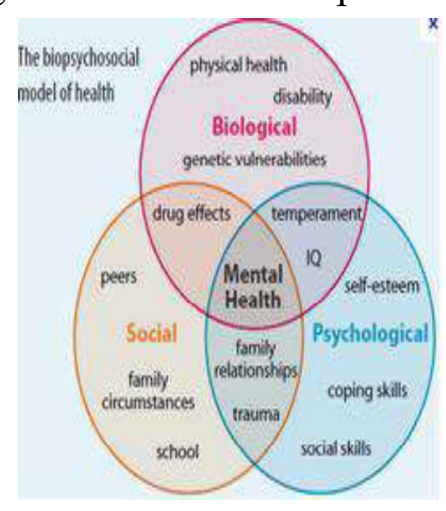

Fig (3)

\section{Types of Drugs}

Sania (2010) [29] found 3.12\% Phyathaddrin, 52.5\% Phencyclidine, 23.12\% Heroin, 44.38\% Charas, 30\% Marijuana, 41.25\% Ecstasy, 39.38\% Cocaine, 86.87\% Ganja and 16.25\% LSD. The use of phencyclidine, Charas and Ganja are greater than normal, in quantity, because the price is minimum and easy available. Sania, according to his investigation, found that the number of defendants who experience drug abuse: was $66.87 \%$ from the population, having tried drug irregular intervals, whilst $33.13 \%$ have tried drugs regularly. Furthermore, he found the main cause of Drug addiction that $15.62 \%$ defendants get addicted because of failure in love, $13.75 \%$ because of trying to forget family confections, $38.75 \%$ because influenced by friends and $31.88 \%$ because of just trying for fun.

Taremian et al.; (2018) [30] indicated that Substance employment is great relating to disorder of mental health anxiety 
among university students. It might result in emphasizing the behaviour of academic problems, contagious diseases, and psychiatric disorders. His research is a formal inquiry to discover and examine the facts of the hazard and protective influence that contributes to a result or outcome of abuse of substance among Iranian university students.

The major factors influencing addiction drugs university students could be classified as [30]:

- Significantly, having a negative attitude toward university consequently using all types of substance except legal medications.

- Suffering anger and aggression.

- Depression and anxiety.

- A positive sympathy situation towards abusing substances.

- Deficiency of religious beliefs.

- Family conflicts [30],

- Students from unsettled families are willing to be involved in drug abuse.

- Bad treatment relating to peers and family member.

- Positive parent's attitude towards significantly and strongly predicted using hard drugs instead of the use of prescribed medical treatment.

- Low confidence in one's own with positively using the illegal substance.

- Become aware or conscious of the availability of illegal hard drugs and utilizing prescribed medications' consumption for a different situation.

- Peers' affirmative behavior toward drugs anticipated illegal substances [31].

- Adolescents living in less than the average social economic standard (SES) [32],

- Adolescents are subjected to psychopathology [33].

\section{Role of educator counselling in controlling drug and substance abuse \\ Drug abuse educator counsellors supply the required assistance systems for individuals recovering from drug abuse, illegal substance issues for addicts and other related issues. By establishing a connection based on trust with their students drug abuse patients,}


educator counsellors introduce the support, resources, and to -free make considered decision guidance for their student patients to be able to employ to complete their way to addiction retrieval.

It was reported [33] that the trust of student patients through a therapeutic alliance is to feel secure with their educator counselors. Furthermore, the educators allowing them to feel susceptible and isolating out of their problems and effectively work together even during tribulation. Strong alliances with this sort of trust, the trust between the student patients' views will ensure that their educator counselors are trustable.

Stacy \& Ames (2001) [35] have explained that Educators counselors can link obtained information and expertise to possibly "high risk" student patients.

(American School Counsellor Association [ASCA] (2005)[36] has proposed that as drug abuse, students need highly specified advocacy and educator. Counsellors can make this support easy by unifying university counselors together as one vision and voice, which originates unity to focus towards students becoming better achievements.

Ratts \& Hutchins (2009) [37] and his colleagues emphasized that as the counselors support at the individual level, it is substantial to support potentially, at not only one level but can often lead counselors to interfere at other levels of the support Competencies. They continue, with students at high risk for drug abuse coming into contact with educator counselors on a harmonic basis. However, educator counsellors preferably exist to provide and support a patient's patient intentionally that belonged to risk factors. In this case, it could lead to drug abuse. Educator counselors' ability to distinguish students' risk factors and obstacles that prevent students from gregarious, personal, and academic development. They reported that educator's counselors can treat all aspects of the students in the surrounding environment (e.g., school, home, and general activities) by working jointly and actively with community society, parents, or other educators, as well as other stakeholders. Not only that, but bring students and parents together into contact with community support to supply the required support.

Sussman et al., (2008) [38] has facilitated the therapy by speaking about the possibilities of sources of environment such as 
access to progress of education, activity done for enjoyment and entertainment, transportation, and drug user/counselling duties in his community. Furthermore, educator counselors have to perform their duties as communication for students as they are family, academic, and social interests. All of this discussion would be of great significance aspect of counselling.

ASCA, (2005) [39]; insisted that educators are believed to be trained in supplying mental convenience development and fitting in well with a student's programming. They should, therefore, be serving as an instrument for bringing together or into contacting students to produce available support and coincide with their psychosocial statement. It emphasized that responsibility to achieve student addiction prevention progressing in particular, is required to be done to prove the validity of progress to serve as an official record of students' drug abuse, as a case of risk and factors of protection. On behalf of educators to provide indirect services as a result of the educator counselors' to take part with others contain referrals for supplementary reinforcement, consultation and cooperation with the help of parents, educators, and civilian society organizations.

Comerci and his colleague (2000) [40] Emphasized getting parents to cooperate on the students' prevention schedules. Parents, however, are necessary to enhance the students' success. Eventually, educator's counselors are able to coordinate and raise the parent training and participation on the level of construction.

Sussman.et al., (2008) [41] proposed that concerning students who are under prohibited drug abuse, the use of behavioural and cognitive behavioural can help educator counselors to focus on diminishing the rate of behaviours consistent with drug abuse. On the other hand, to maximize the rate of behaviours opposed to drug abuse.

McLaughlin et al., (1993) [42] have proposed that Educator counselors combine their counselling with students forming, figuration, act of imitating the role of a student addiction, and affirmation training into their work with students at risk. In addition, by using the techniques of behavioural and cognitive behavioural, and by using problem solving with decision-making programmes, they can help students to overcome their problem with addiction. Furthermore, using skills, positive affirmation, thought stopping to 
Avoid Panic and Anxiety to replace the negative with positive and realistic thoughts.

Vavakova (1998) [43] has introduced a social contracting between Governments, Universities and Society where the mechanism of social contracting would allow universities to contract with civilian society to deliver prevention programs to key influenced university populations.

Botvin, et al., (1995) [44] indicated that educator counselors can provide support, confidence or hope for students to get involved in university community life. Research specified that adolescents who feel involved and sentimentally connected and attending to higher education are less probable to get engaged in drug abuse than students who feel incoherent from their peers.

Pate and his colleagues (2000) [45]., relating to or denoting behaviour or a result of activities which are positive, useful, and intended to promote social acceptance and friendship such as sports, can conserve against drug abuse.

In order to more completely and entirely understand the exclusive social-ecology of urban youth, Mason et al., (2009) [46] have used a technique of GIS (geographic information system) for the study in this field. They reported that regardless of the challenges of using GIS for this study, it is believed that GIS is an essential tool to assist the construction of geography in that field's effectiveness. Work is required to define micro-level geographic data that affects urban teenagers' health reactions. This technique contains sociospatial variables as well as contextual. The research revealed a unique level of intervention. However, the next step of this technology application is to streamline the data collection. Eventually the data will be analyzed and presented to apply to real-life settings. Such technology will be useful in areas such as primary care and community centers, in addition to urban schools.

Therapeutic associations between the educator and student patients can be strongly formed by [47]:

- The patient should know that educator are curios in their wellbeing

- Pay attention during sessions 
- Allow patients to know that educator can understand and share their feelings with their problems.

- Communicating sympathetically with foundational issues during the period of recovery.

Richard, et al.; (2006) [48] reported that the ultimate direct person for information about the obstacle that prevents connection with treatment is the drug abusers themselves, although their views have not always been considered.

\section{Drug awareness campaigns and punishment}

Diana and her colleagues (2019) [49] the most popularly measures used are guidance and counselling, punishment and (suspension). The recommendations of the study are as follows, instead of punishment for those students found abusing drugs in school, they should be counselled. They also felt that guidance and counselling departments should be strengthened with counsellors equipped with knowledge and skills to handle students with drug problems. Furthermore, the response also suggested that educational administrators should make arrangements to have a forum to educate parents, educators, students and the educational community on how to curb drug abuse.

\section{Result and Conclusion}

The research is mainly based on university students who were drugged with abuse at the time of teenage (adolescent). Most respondent's ages lay on a 20 to 25 -year-old and a few of them lay on a 15 to 19 -year-old. The male VS female respondents are reluctant to talk about it. Infrequently or irregular intervals, however, most numbers of respondents tested drugs.

To the greatest extent, illegal substances include a substance that raises levels of physiological or nervous activity in the body are opioids, and benzodiazepines, a drug or other compound that inhibits the physiological effects of histamine, used especially in the treatment of allergies.

According to this investigation, the male is regularly or habitually taking drugs more than female, whilst female takes the drug at irregular intervals. Females fundamentally are perceptible that it can damage only a little of their body with the drug addiction, and they accept it as fun. Moreover, most of them disbelieve that at any 
time they could be free from addiction. Every addict begins as infrequently and irregularly user, and that foremost taken, is optional, and under control. As time passes, however, drug use continues in more subtle ways that can result in compulsive and even uncontrollable drug use.

The result of hypotheses testing suggests that university students can become addicted to drugs by the influence of frustration and peer group.

Therefore, this feedback may help the authorities and planners of the government, non-government, side by side the communities to take place for adequate initiative action and must be taken to prevent further society drug addiction.

The resolution, as reached after typically over a period of seeking therapy for addiction, is not an easy way, and demands a great deal of confidence between student patients and their educator counsellors. As such, educator counselors should be careful to originate a strong connection with their patients, recognized as a therapeutic association.

\section{Recommendation}

Time is fully prepared for leaders at the highest level to wake up to the danger posed by the healthy existence of society as more and more new addicts join the ranks of the hardcore ones. This small sector must be arrested at all costs. Political obligation is essential to fight unlawful drug-traffickers who absorb the life of innocent students and turn into rich by smuggling of drugs. Preventive education programs against drug abuse are fundamentally required (Greydanus.2003)[50]. Drug trafficking should be prevented by the execution of laws and suppression. The whole society should take part in realization of developing programs and peer-counseling is a substantial part of changing the negative attitude of teenagers.

Carter and his colleague (2005)[51] reported that Healthy relationships of parent-teenagers, with a positive connection, and communication modalities as well as adequate highly organized supervision accomplishment with anti-substance abuse discussions, will help to resist risk factors and minimize drug abuse (Carter.2005)[50].

Finally, mutual action by peers who display positive behaviour may perform as preventive factors and assist in minimizing drug abuse disposals (Walker .2006)[51]

Leslie et al., (2006)[52] considered the social-ecological profiles, specific and empirical derived could be used as a starting 
point for the addicted person to supply appropriate interventions to teach teenagers prevention skills that are ecologically based. They recommended how to utilize social networks to enhance the spending network period in a safe place with safe network colleagues. Such designs to meet someone's individual requirements interventions could be more appropriate, clearly identified, and thus be more sufficiently successful in producing the desired effect.

\section{References}

[1] World Drug Report (2005) .Retrieved from.https:/www.unodc.org/unodc/en/dataAnd-analysis/WDR-2005.html.

[2]United Nations, June 2018. All rights reserved worldwide. ISBN: 978-92-1-148304-8 El SBN: 978-92-1-045058-4 United Nations publication, Sales No. E.18.XI.9.

[3]Washington (DC): US Department of Health and Human Services; 2016 Nov. Facing Addiction in America: The Surgeon General's Report on Alcohol, Drugs, and Health. Chapter 4.

[4]EMCDDA (2010) United Kingdom drug situation .NATIONAL REPORT (2009 data) To the EMCDDA by the Reitox National Focal Point.: annual report to the European Monitoring Centre for Drugs and Drug Addiction (EMCDDA) 2010.

[5] Dawson, S. (2019). Barriers to Attaining Higher Education Among Substance

Abuse Counselors.

[6]Zaman,M.; Razzaq,S.; Hassan.; Rahman,F.; Fazal,C. and Chughtai R.(2015).Drug abuse among the students.Packistan journal of pharmaceutical research.vol.1.issu 1.

[7]Maithya, W.R., (2009): Drug abuse in secondary schools in Kenya. Developing a program for prevention and intervention. Ph.D. Thesis, University of South Africa, Pretoria, South Africa.

[8]Botvin, G.J., Griffin, K.W. \& Gilchrist.L.Z. (2013).Drugs and Alcohol Abuse School, college. Retrieved from http://education.stateuniversity. com/pages/1923/Drug-AlcoholAbuse.html.

[9]NACADA (2008). Annual Report for the Office of the National Campaign against Drug Abuse in Nairobi NYA.

[10] Md. Abul-Hasam1 \& Md. Mushahid. (2017).Drug Addiction in Urban Life of Bangladesh: A Sociological Study for Exploring the Causes. Asia Pacific Journal of Multidisciplinary Research, Vol. 5, No. 2, May 2017 
[11]Glynn TJ. (1989) .Essential elements of school based smoking prevention program. J Sch Health.59:181-188.

[12] DHHS .Healthy People (2000). Washington, DC: US Dept. of Health and Human Services; 1988.DHHS publication no. PHS 9150212.

[13] Susan T. Ennet, Nancy S. Toble, Christopher L. Ringwalt, and Robert L. Flewelling. (2004). How Effective Is Drug Abuse Resistance Education? A Meta-Analysis of Project DARE .Outcome Evaluations. Am J Public Health.V.94 (6).

[14] Steven L. West; and Keri K. O'Neal. (2004).Project D.A.R.E. Outcome Effectiveness Revisited. American Journal of Public Health.2004, Vol 94, No. 6.

[15] Adroom M.; Gorgij, H.Ch. Okati, M.; Mohana, Sh.; and Sharafi, Z. (2016).Study the Relationship between Frustration Tolerance and Tendency to Drug Abuse among Students from Payame Noor University, Zahedan Branch.The Social Sciences 11 (14): 36273630 ,

[16] Abul-Hasam, Md. \& Mushahid, Md.) (2017). Drug Addiction in Urban Life of Bangladesh: A Sociological Study for Exploring the Causes. Asia Pacific Journal of Multidisciplinary Research, Vol. 5, No. 2,

[17]Yusuf, F .A. (2011). Factors Influencing Substance Abuse among University Students in Osun State, Nigeria. DOI: 10.4314 /afrrev.v4i4.69233.

[18]Bechara, A. (2005) .Decision making, impulse control and loss of willpower

resist drugs: A neurocognitive perspective. Nat. Neurosci. 2005, $8,1458-1463$.

[19]Wing Lo. T.; et al (2019).The Association between Substance Abuse and Sexual Misconduct among Macau Youths. Int. J. Environ. Res. Public Health 2019, 16, 1643; doi: 10.3390/ijerph16091643.

[20] Mikhail, M. N.; Eissa, M.A.; Labeeb, Sh. A. \& Abd El-Hamid, S. M. (2001).The Psychosocial Aspects of Drug Addicts in Assiut Governorate. Ass. Univ. Bull. Environ. Res. Vol. 4 No. 2.AUCES

[21] Abdel-Mageid, R. (2017). Estimation of the Prevalence of Tramadol and Cannabis Abuse among Drivers Involved in Road Traffic Accidents Admitted to Alexandria Main University Hospital: A Prospective Study. International Journal of Contemporary Medical Research. Vol 4. Issue 4. 
[22] Chadda, K., and Chatterjee, B. (2018) .Need for psychosocial interventions: From resistance to therapeutic alliance. Indian journal of psychiatry.Vol .60 .Issue 8.Page: 440-443.

[23] Alvarez FJ, Gonzalez-Luque JC, Segui-Gomez M. (2015) Drugs, Substance Use Disorder and Driving: Intervention of Health Professionals in the Treatment of Addictions. Adicciones. 2015; 27:161-7.

[24] European Monitoring Centre for Drugs and Drug Addiction.( 2016 ) Perspectives on drugs: The role of psychosocial interventions in drug treatment; Retrieved from: emcdda.europa.eu/topics/pods/psychosocial-interventions.

[25] Flora, K., Stalikas, A. (2013). Factors affecting substance abuse treatment across different treatment phases. International Journal of Psychosocial Rehabilitation, 17 (1), 89-104.

[26] Jonathan N. O.; Ihedi. O.E. (2016). Relationship between Parent's Drug Use, Peer Group Influence and Adolescents' Addictive Behaviour. International Journal of Humanities Social Sciences and Education (IJHSSE) Volume 3, Issue 5, PP 1-8.

[27 Fuligni, A. J.; Eccles, J. S.; Barber, B. L.; \& Clements, P. (2001).Early adolescent peer orientation and adjustment during high school. Journal of Development Psychology 37:2836.

[28]Naz, N.N., (2015). The Effect of Substance Abuse on the Quality Of Life of The Use. A thesis submitted in total fulfillment of the requirement for the of degree: Bachelor of Science in Occupational Therapy .Bangladesh Health Professions Institute (BHPI) .Faculty of medicine University of Dhaka.

[29] Sania, M.N. (2010).Drug addiction among undergraduate students of private universities in Bangladesh. Procedia Social and Behavioral Sciences 5 (2010) 498-501.

[30] Needle et al (2001), Youths from disrupted families' involvement in substance abuse. Monitoring the Future National Survey Results on Drug Use. National Institute On Drug Abuse. Volume I. (09-7402). p.721.

[31] Sussman, S., Dent, C. W., \& Leu, L. (2000). The one-year prospective prediction of substance abuse and dependence among high-risk adolescents. Journal of Substance Abuse, 12, 373-386.

[32] Hamilton, H., Noah, S., \& Adlaf, E. (2009). Perceived financial status, health and maladjustment in adolescence. Social Science \& Medicine, 68, $1527-1534$. 
[33] Sussman, S., Skara, S., \& Ames, S. L. (2008). Substance abuse among adolescents. Substance Use \& Misuse, 43,1802-1828.

[34]W. University .The Role of the Counselor in Addiction Recovery. $\quad$ Retried from. https://counseling.online.wfu.edu/blog/the-role-of-the-counselorin-addiction-recovery/.

[35]Stacy, A. W., \& Ames, S. L. (2001). Implicit cognition theory in drug use and driving under the influence interventions. In S. Sussman (Ed.), Handbook of program development in health behavior research and practice (pp. 107-130). Thousand Oaks, CA: Sage.

[36] American School Counselor Association (ASCA) pp2. (2005). The ASCA national model: A framework for school counseling programs (2nd Ed.). Alexandria, VA: Author.

[37] Ratts, M. J., \& Hutchins, A. M. (2009). ACA advocacy competencies: Social justice advocacy at the client/student level. Journal of Counseling \& Development, 87, 269-275.

[38] Sussman, S., Skara, S., \& Ames, S. L. (2008). Substance abuse among adolescents. Substance Use \& Misuse, 43, 1802-1828.

[39]ASCA.American School Counselor Association. (2005). The ASCA national model: A framework for school counseling programs (2nd Ed.). Alexandria, VA: Author (pp. 4).

[39] Comerci, G. D., \& Schwebel, R. (2000). Substance abuse: An overview. Adolescent Medicine, 11, 79-101.

[40]Sussman, S.; Skara, S.; \& Ames, S.L. (2008). Substance abuse among adolescents. Substance Use \& Misuse, 43, 1802-1828.

[41]McLaughlin, T.F., \& Vacha, E.F. (1993). Substance abuse prevention in the schools: Roles for the school counselor. Elementary School Guidance \& Counseling, 28, 124-132.

[42] Vavakova, B. (1998). The New Social Contract between Governments, Universities and Society Minerva. vol. 36, no. 3, the endless transition: a "triple helix" of university-industrygovernment relations (autumn 1998), pp. 209-228. Springer.

[43]Botvin, G. J.; Baker, E.; Dusenbury, L.; Botvin, E. M.; \& Diaz, T. (1995). Long-term follow-up results of a randomized drug abuse prevention trial in a white middle-class population. Journal of the American Medical Association, 273, 1106-1112

[44]Pate, R. R., Trost, S. G., Levin, S., \& Dowda, M. (2000). Sports participation and health-related behaviors among US youth. Archives of Pediatrics \& Adolescent Medicine, 154, 904-911. 
[45] Mason, M.; Cheung, I.; Walker. (2009). Creating a Geospatial Database of Risks and Resources to Explore Urban Adolescent Substance Use .Journal of Prevention \& Intervention in the Community , 37:1,21-34

[46]Natoya H. Haskins.(2012). The School Counselor's Role With Students At-Risk for Substance Abuse. Ideas and Research You Can Use: VISTAS 2012, Vol1.

[47]Richard, C. R.; Jiangmin Xu.; Carey A. Carr, D. Lane, T.; Wang, J.; and Carlson, R. Treatment barriers identified by substance abusers assessed at a centralized intake unit. J Subst Abuse Treat. 2006 Apr; 30(3): 227-235.

[48]Diana. Doumas, R. M. , and Miller S. Esp., (2019) .Continuing Education in Motivational Interviewing for Addiction Counselors: Reducing the Research-to-Practice Gap. Journal of Addictions and Offender counseling. Volume 40, Issue 1.

[49]Greydanus, D. E., Patel, D. R., \& Pratt, H. D. (2003). Behavioral pediatrics. Pediatric Clinics of North America, 50, 741-1231.

[50] Carter, B., \& McGoldrick, M. (Eds.). (2005). The expanded family life cycle: Individual, family and social perspectives (classic ed.). Boston: Allyn \& Bacon.

[51]Walker, L. Mason, M., \& Cheung, I. (2006). Adolescent substance use and abuse prevention and treatment: Primary care strategies involving social networks and the geography of risk and protection. Journal of Clinical Psychology in Medical Settings, 13(2), 126-134.

[52] Leslie R.; Mason W.; Cheung,I. (2006)Adolescent Substance Use and Abuse Prevention and Treatment: Primary Care Strategies Involving Social Networks and the Geography of Risk and Protection .Journal of Clinical Psychology in Medical Settings 13(2):126-134. 